Revista de Estudios Histórico-Jurídicos

[Sección historia del pensamiento político]

XLIII (Valparaíso, Chile, 2021)

[pp. 723-747]

\title{
LA ARBITRARIEDAD DEL PODER: LA PALABRA Y LA IDEA EN LA HISTORIA CONSTITUCIONAL
}

[Arbitrary use of power: The word and the idea in the constitutional history]

"Alli donde termina la ley, empieza la tiranía"

John Locke,

[Segundo tratado sobre el Gobierno Civil: un ensayo acerca del verdadero origen, alcance y fin del gobierno civil, 1689]

\author{
Agustín Ruiz Robledo* \\ Universidad de Granada, España
}

\begin{abstract}
Resumen
Este trabajo surge de la convicción de que se ha estudiado exhaustivamente lo que podríamos llamar la vertiente positiva de la historia del Estado de Derecho, sobre todo la separación de poderes; pero no se ha estudiado tanto su vertiente negativa, el concepto de arbitrariedad y cómo ha sido percibida esta por los ciudadanos a través de la Historia. Para ello, tras un rápido repaso a los precedentes clásicos y de la Edad Media (con la Carta Magna a la cabeza), se analizan las tres grandes revoluciones modernas contra el poder arbitrario: la inglesa del siglo XVII y la americana y la francesa del XVIII, para a continuación estudiar la lucha española del siglo XIX. El análisis de estos grandes momentos históricos nos lleva a un resultado muy sugerente para el mundo jurídico: la distinta percepción de quien era el poder arbitrario (el rey en Inglaterra, el Parlamento en Estados Unidos y el rey y sus tribunales en Francia y España) llevó a una diferente articulación de la común división de poderes, con mecanismos de control de la arbitrariedad política
\end{abstract}

\begin{abstract}
The main purpose of this study, based on the conviction that what we might call the positive aspect of the history of the Rule of Law, especially the separation of powers, has been thoroughly studied, is to examine its negative aspect, i.e., the arbitrariness concept and the manner in which citizens have perceived it throughout history. To address this matter, first there is a brief review of the historical background of the Ancient Times and the Middle Ages (with emphasis on the Magna Carta). Secondly, the three major revolutions of Modern Times against the arbitrary use of power are analyzed: the English Revolution of the $17^{\text {th }}$ Century, the American Revolution and the French Revolution of the $18^{\text {th }}$ Century and then the Spanish Revolution of the $19^{\text {th }}$ Century. The analysis of these important historical times provides a very interesting result to the judicial sphere: the different perception of the one holding the arbitrary power (the King in England, the Parliament in the United States of America and the King and its Courts in France and
\end{abstract}

* Catedrático de Derecho Constitucional, Universidad de Granada. Plaza de la Universidad, 1, 18071 Granada (España). Dirección electrónica: arobledo@ugr.es. ORCID 0000-00022212-3816. 
eficaces en Estados Unidos y Gran Bretaña y bastante menos, en Francia y España.

\section{Palabras clave}

Gobierno arbitrario - separación de poderes - Estado de derecho - revolución americana - revolución inglesa - revolución francesa.
Spain) led to a different articulation of the common division of powers, with efficient mechanisms to prevent the arbitrary use of power in politics in the United States of America and Great Britain and rather less efficient in France and Spain.

\section{KEY WORDS}

Arbitrary Government - Separation of Powers - Rule of Law - American Revolution - English Revolution - French Revolution.

RECIBIDO el 11 de febrero de 2020 y ACEPTADo el 1 de abril de 2021

\section{INTRODUCCIÓN}

El Diccionario de la Real Academia española define la arbitrariedad como la "cualidad de arbitrario" y el adjetivo arbitrario como "sujeto a la libre voluntad o al capricho antes que a la ley o a la razón". Todas las lenguas romances, desde el rumano al portugués ${ }^{1}$, tienen hoy esa acepción peyorativa de arbitrario partiendo de un primer significado puramente descriptivo de decisión producto de la libre voluntad. Lo mismo se puede decir del inglés arbitrariness -que incluso toma la palabra de la misma fuente que nosotros, del sustantivo latino arbitrarius $^{2}-\mathrm{y}$ del alemán Willkürlichkeit'. En especial, el Diccionario de la Academia Francesa expresa con gran claridad lo que podríamos llamar arbitrariedad política: "Caractère ou ensemble des actes d'un gouvernement où la volonté, le bon plaisir des personnes remplace l'autorité de la loi'.

Es decir, la arbitrariedad designa el gobierno sin reglas y límites, de tal forma que un poder arbitrario es el reino del despotismo. Por no decir, cargándonos de ironía, que la arbitrariedad política solo conoce una ley, la ley del encaje que es "la resolución que el juez toma por lo que a él se le ha encaxado en la cabeza, sin tener atención a lo que las leyes disponen"4.

${ }^{1}$ Cfr. el interesante recorrido por los diccionarios de las principales lenguas europeas que realiza Fernández, Tomás-Ramón, Arbitrario, Arbitraire, Arbitrary. Pasado y presente de un adjetivo imprescindible en el discurso jurídico (Madrid, 2016), pp. 11 y ss.

${ }^{2}$ Según Keach, el préstamo no se tomó directamente del latín, sino por medio del francés antiguo. Vid. KeAch, William, Arbitrary Power: Romanticism, Language, Politics (Princeton, 2005), p. 3.

${ }^{3}$ En alemán "Wilkur" originariamente no tenía ningún sentido peyorativo, significaba solo la libertad de elección en oposición a una actuación legalmente exigible. Cfr. STARCK, Christian (comp.), Recht und Willkërr (Tubingen, 2012), p. 2. También el clásico, EBEL, Wilhelm, Die Willkür. Eine Studie zu den Denkformen des älteren deutschen Rechts (Göttingen, 1953). En alemán también se usa “Arbitraritäl” si bien se emplea más en semiótica, raramente en derecho.

${ }^{4}$ Covarrubias, Sebastián de, Tesoro de la lengua castellana (1611, ed. facsímil Madrid, 1977), p. 466. Por su parte, Miguel de Cervantes hizo que don Quijote aconsejara de esta manera a Sancho cuando fue nombrado gobernador: "Nunca te guíes por la ley del encaje, que suele tener mucha cabida con los ignorantes que presumen de agudos". [Segunda Parte del Ingenioso Hidalgo Don Quijote de la Mancha (1616, ed. de John Jay Allen, Madrid, 1978), p. 342]. 
Precisamente, el objeto de este trabajo es el de estudiar cómo se ha desarrollado históricamente la lucha contra la arbitrariedad de los poderes públicos, que allí donde ha triunfado ha desembocado en el Estado constitucional. Este, en cualquiera de sus formas, responde a la misma idea de limitar la arbitrariedad del poder político, como muy bien supo ver Jellinek a principio del siglo XX: "la doctrina inglesa de checks and balances, la francesa de la división de poderes, la alemana del Estado de derecho, todas ellas se proponen como fin último, fijar límites a

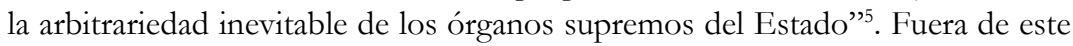
Estado sometido a límites, regido por las leyes, solo impera la arbitrariedad, sea en forma de Estado absoluto, despotismo ilustrado, dictadura del proletariado o cualquier otra modalidad de poder irresponsable y sin límites. Por eso, en fecha tan dramática como 1936, McIlwain acertó plenamente al escribir: "El único gran problema que eclipsa a todos los demás en el mundo convulsionado de hoy es la cuestión entre el constitucionalismo y el gobierno arbitrario. Más profundo que el problema de si vamos a tener un sistema capitalista o algún otro consagrado en nuestra ley, está la cuestión de si vamos a ser gobernados por la ley o sólo por voluntad arbitraria"'.

\section{LA LUCHA CONTRA LA ARBITRARIEDAD EN LA ANTIGÜEDAD}

La idea del poder arbitrario entendido como una forma de organización en el que el poder político puede actuar como considere conveniente, sin ningún tipo de límites, ha preocupado profundamente a la cultura occidental desde la antigüedad clásica. Así, muchos autores reflexionaron sobre cómo controlar el poder para evitar que fuera despótico: desde Platón (que señaló en Las leyes que la "salvación de la ciudad" depende de que los gobernantes sean "sus esclavos") y Aristóteles (en su Política defendió la superioridad de la ley "como razón sin apetencia" frente a la voluntad de los gobernantes) hasta Cicerón ("seamos siervos de la ley para poder ser libres") y Marco Aurelio ("el fin de los seres racionales es obedecer la razón y la ley de la ciudad y constitución más venerable”) ${ }^{7}$. De todos los textos que se podrían citar, quizás merezca la pena recordar la Antígona de Sófocles (escrita alrededor del 441 a. C.), no solo por su fuerza literaria, sino porque expresa muy elocuentemente la creencia de los griegos en que el poder político no puede ser omnímodo:

"Creonte. (A Antígona) Y tú, tú que inclinas al suelo tu rostro ¿̇confirmas o des-

${ }^{5}$ JellineK, Georg, Allgemeine Staatslehre (1905, trad. de Fernando de los Ríos: Teoría general del Estado (Buenos Aires, 1981), p. 271.

${ }^{6}$ Mcilwain, Charles Howard, Government by Law, en Foreign Affairs, 14/2 (1936), p. 185. Este espectacular artículo se recogió luego en ÉL Mismo, Constitutionalism and the Changing World (Cambridge, 1939), p. 266 y ss.

${ }^{7}$ La frase de Platón está en sus Leyes, 715 d. y la de Aristóteles en su Política, 1287a. Para un recorrido por las opiniones de los filósofos griegos sobre el control del poder político vid. May, Christopher, The Rule of Law: Athenian Antecedents to Contemporary Debates, en Hague Journal on the Rule of Law, 2/4 (2012), pp. 235-251. La conocida frase de Cicerón -relanzada por Montesquieu- "Omnes legum servi sumus ut liberi esse possimus" está en su Pro Aulo Cluentio Habito, párrafo LIII.146. La de Marco Aurelio es de sus Meditaciones, párrafo 16. 
mientes haber enterrado a tu bermano? ANTíGONA. Lo confirmo, sí, yo lo bice y no lo niego. Creonte. ¿Sabias que estaba decretado no hacerlo? AntíGONA. Si, lo sabia: ¿cómo no iba a saberlo? Todo el mundo lo sabe. CREONTE. $Y$, asi y todo, ¿te atreviste a pasar por encima de la ley? Antígona. No era Zeus quien me la habia decretado, ni Dike, compañera de los dioses subterráneos, perfiló nunca entre los hombres leyes de este tipo. Y no creía yo que tus decretos tuvieran tanta fuerza como para permitir que sólo un hombre pueda saltar por encima de las leyes no escritas, inmutables, de los dioses: su vigencia no es de hoy ni de ayer, sino de siempre, y nadie sabe cuándo aparecieron".

Si preferimos un texto más directamente político, uno de los clásicos que mejor expresa en pocas palabras lo que es un gobierno arbitrario es el discurso de Andócides contra Alcibiades, realizado a principios del siglo IV a. C.: "Cuando él a unos los despoja, a otros los golpea y a otros los encarcela y a aquéllos les exige dinero, pone de manifiesto que la democracia no tiene ningún valor, puesto que él pronuncia discursos de demagogo y lleva a cabo actos de tirano, pues sabe bien que vosotros ponéis atención a esa palabra, pero que no os preocupa su realización".

Pero no solo en la teoría, en la práctica también en Grecia y Roma se luchó contra la arbitrariedad fijando por escrito las leyes para que el derecho fuera conocido por los ciudadanos y los gobernantes, en general, y los jueces en particular, no pudieran interpretarlo a su capricho. Algo que no parece haber existido en otras culturas antiguas como la india o la china, más desarrolladas técnicamente que la europea durante milenios ${ }^{10}$. Así, sabemos que las leyes escritas de Dracón en el siglo VII a.C. fueron pensadas para que los jueces atenienses no pudieran manipular las leyes en favor de los nobles ${ }^{11}$. Con una función similar, los romanos redactaron en el siglo $\mathrm{V}$ a. C. la Ley de las Doce Tablas porque antes de ella el pueblo estaba -en palabras de Sexto Pomponio en el Digesto- "sine lege certa, sine iure certo, omniaque manu a regibus gubernabantur" (sin una ley determinada, sin un derecho determinado, y todas las cosas se gobernaban por el poder de los reyes). El propio Digesto, aprobado en el 533, y los demás textos incorporados al Corpus Iuris Civilis fueron concebidos por el emperador Justiniano y sus juristas para acabar con el ius incertum y el ius controversum que permitían que los jueces dictaran sentencias arbitrarias ${ }^{12}$.

No parece que los romanos usaran "arbitrarius" con el sentido moderno de caprichoso, al menos no en los textos jurídicos, ni tampoco en los políticos, ni

\footnotetext{
${ }^{8}$ Sófocles, Antígona (trad. de Assela Alamillo, Madrid, 2014), p. 115. Un trabajo interesante sobre la arbitrariedad en el teatro de Sófocles y otros autores clásicos es SANDEFUR, Timothy, Love and Solipsism: Law and Arbitrary Rule in Aeschylus, Shakespeare, Sophocles, and Anouilh, en Alabama Law Review, 64/5 (2013), pp. 1004-1011.

${ }^{9}$ Contra Alcibiades. Cito por Andócides, Discursos (trad. y ed. bilingüe de Gerardo Ramírez Vidal, México, 1996), p. 10.

${ }^{10}$ JeLLinEK, Georg consideraba que el poder arbitrario era "la nota común a Oriente", cit. (n. 5), p. 218, mientras que en Atenas "Todas las prestaciones al Estado descansaban en fundamentos legales, con lo cual, de un modo análogo a lo que acontece en el Estado moderno, impedíanse las valoraciones arbitrarias" (p. 232).

${ }^{11}$ Vid. Carawan, Edwin, Rhetoric and the Law of Draco (Oxford, 1998).

${ }^{12}$ Cfr. Ana Martín Minguijón, Digesto. Una auténtica obra legislativa (Madrid, 2013). La cita de Pomponio está en Digesto 1, 2, 2, 1.
} 
siquiera en aquellos escritos para combatir lo que hoy llamaríamos, sin duda, un poder arbitrario ${ }^{13}$. Tuviera o no límites la máxima de Ulpiano (Digesto 1, 3, 31) Princeps legibus solutus est-cuestión sobre la que discute la doctrina ${ }^{14}$ - lo cierto es que en el derecho romano no aparece el sentido negativo de arbitrario, solo el positivo de decisión propia y autónoma de una persona ${ }^{15}$. Sí que existía la "actio arbitraria" que era la acción para someterse voluntariamente a un árbitro para que este resolviera un conflicto entre partes, no según las leyes, sino su libre decisión, su albedrío. Así, mientras el iudex emitía un iudicium, el arbitrer, un arbitrium; en ambos casos la decisión era obligatoria, si bien el sometimiento al arbitraje era voluntario. Hasta nuestros días ha llegado este concepto de arbitraje, que por razones evidentes no forma parte del objeto de estudio de esta investigación ${ }^{16}$.

\section{LA CARTA MAGNA INGLESA. EL GRAN TEXTO CONTRA} LA ARBITRARIEDAD EN LA EDAD MEDIA

La Edad Media, con su sentido patrimonial de la organización política y el gran aislamiento de las poblaciones, fue una época histórica en la que predominó el derecho consuetudinario, aplicado habitualmente por los señores feudales. Por tanto, era un territorio abonado para la arbitrariedad y poco dado a la seguridad jurídica. La lucha contra ella no se hizo tanto buscando la legislación abstracta de carácter general, sino los derechos subjetivos de determinados colectivos ${ }^{17}$. Así

\footnotetext{
${ }^{13}$ Por ejemplo, no se menciona la palabra (ni en el original griego ni en la versión latina) en la Primera Apología de Justino Mártir (alrededor del 150 d. C.) dirigida al emperador Antonio Pio para convencerlo de lo injustas que era las leyes contra los cristianos. El escrito es un alegato tan claro contra el poder arbitrario que el trabajo más exhaustivo que existe sobre él recoge ese aspecto en el título: Keresztes, Paul. Law and Arbitrariness in the Persecution of the Christians and Justin's First Apology, en Vigiliae Christianae, 17/1 (1963), pp. 204-214.

${ }^{14}$ Los especialistas modernos mantienen mayoritariamente la tesis de que en el Digesto la expresión Princeps Legibus Solutus quería decir que el emperador podría declararse a sí mismo que, de forma excepcional, no estaba sujeto a la legislación (como el Senado podía hacer en la República para ciertas personas en relación con ciertas leyes), mientras que en la Edad Moderna se usó para legitimar, sin ninguna restricción, los poderes absolutos de emperadores y reyes, vid. Wyduckel, Dieter, Princeps Legibus Solutus. Eine Untersuchung zur frühmodernen Rechts- und Staatslebre (Berlin, 1979).

${ }^{15}$ Así, por ejemplo, el historiador Marco Juniano Justino (s. II) comienza su Epitome de las "Historias filípicas" de Pompeyo Trogo señalando que en los tiempos antiguos los hombres no se regían por las leyes, sino por los "arbitria principum", pero sin ningún matiz de desvalor [JusTiNo, Marco Juniano, Epitome de las Historias Filípicas de Pompeyo Trogo (trad. José Castro Sánchez, Madrid, 1995), p. 72].

${ }^{16}$ Sobre el arbitraje en Roma, cfr. Gutiérrez García, Cándida, Receptum arbitri (Alicante, 1990).

${ }^{17}$ Cfr. García Pelayo, Manuel, La idea medieval del derecho (1962, Caracas, 2004). Uno de los pocos ejemplos de normas escritas es el Liber iudiciorum aprobado por Recesvinto en el año 654, un código dirigido a establecer un derecho igual para los visigodos y los hispanorromanos en la Península Ibérica. Este texto muestra cómo, al principio de la Edad Media, el adjetivo a r b i t r a r i o todavía no había adquirido su connotación peyorativa y se usaba solo para calificar una decisión propia de las más variadas personas: el príncipe (por ejemplo, para disponer libremente de los bienes que hayan pasado a su propiedad, Libro II, Título $1^{\circ}$ ), el juez (para
} 
abundaban las cartas y pactos feudales en los que -a semejanza de los contratos civiles- los reyes se comprometían con sus vasallos, como por ejemplo, los decretos leoneses de 1188, la Carta Magna inglesa de 1215, la Bula de Oro húngara de 1222 y los Privilegios de la Unión Aragonesa de 1287. Por su enorme influencia histórica, la Carta Magna ha quedado marcada en la historia constitucional como el gran texto medieval contra la arbitrariedad, a pesar de que en él todavía no se emplea esa palabra o sus derivados con el sentido de despotismo que hoy tiene ${ }^{18}$. Sin duda, la Magna Carta Libertatum de Juan sin Tierra, pactada por este rey inglés con un grupo de nobles sublevados, limita el poder arbitrario del rey, hasta entonces regido por el principio vis et voluntas que le permitía actuar como un poder superior a la ley. Se empieza a difundir la idea contraria, expresada en la fórmula feliz de Henry de Bracton: "Non sub homine, sed sub Deo et lege"".

Lord Denning la describió en 1956 como "el documento constitucional más grande de todos los tiempos: la base de la libertad del individuo contra la autoridad arbitraria del déspota" ${ }^{20}$. Y desde luego, en varios artículos se aprecia claramente la prohibición de actos arbitrarios, como el 28 que impide a las autoridades judiciales tomar maíz u otras provisiones sin pagar antes su precio y el 38 que exige a esos funcionarios tener testigos para poder detener. Pero, sin duda, el mandato que mejor representa la limitación de la arbitrariedad es el famoso artículo 39, considerado la base del rule of law: "Ningún hombre libre será detenido, ni preso, ni privado de su propiedad, de sus libertades o libres usos, ni puesto fuera de la ley, ni desterrado, ni molestado de manera alguna, y Nos no pondremos ni haremos poner mano sobre él, a no ser en virtud de un juicio legal de sus pares y según la ley del país"21.

fijar el plazo que estime conveniente a los siervos que proclamen ser libres para que busquen testigos, Libro V, Título $6^{\circ}$ ), el marido (para revocar libremente una donación a su mujer siempre que fuera superior a lo estipulado por la ley, Libro III, Título $1^{\circ}$ ), etc. Disponemos de una excelente edición bilingüe: Ramis SERra, Pedro y Ramis Barceló, Rafael (trad. y notas), El libro de los juicios (Liber iudicorum) (Madrid, 2015). Seis siglos después, Alfonso X el Sabio intenta dar uniformidad jurídica a su reino con una recopilación del ius commune, las Siete Partidas (1265), y cada vez que usa arbitro y sus derivados lo hace con su significado clásico, como en la Ley I del Título IV de la Partida Tercera: " hay aún otros jueces que son llamados en latín árbitros, que muestran tanto como juzgadores de albedrio, que son escogidos para librar algún pleito señalado con otorgamiento de ambas partes" [Vid. Las Siete Partidas, ed. facisimilar de la ed. de 1555, con glosas de Gregorio López (Madrid, 2011), II, p. 38].

${ }^{18}$ Sí que utiliza "a r b i t r i o" y "arbitrium” (artículo 60) en el sentido de decisión personal, propia de los barones, sin la participación del rey, por eso las traducciones inglesas se refieran a "according to their own judgment". Vid., por ejemplo, la traducción de Dan JonEs en su interesante Magna Carta: The Birth of Liberty (Londres, 2016), pp. 132 y ss.

${ }^{19}$ Bracton, Henry de, De legibus et consuetudinibus Angliae (c. 1220, edited by George Woodbine, Cambridge, Mass., 1968), II, p. 33.

${ }^{20}$ Apud Danziger, Danny and Gillingham, John, 1215: The Year of Magna Carta (Londres, 2004), p. 268. Se recogen en este libro otras espectaculares definiciones de la Carta Magna como la de William Pitt, el viejo, que en 1770 la denominó "La Biblia de la Constitución inglesa".

${ }^{21}$ Esta "ley del país" es la base del procedimiento legalmente adecuado o due process of law, expresión que se debe al famoso juez Lord Coke que en 1606 consideró que era la traducción moderna de "per legem terrae" [COKE, Edward, The Second Part of the Institutes of the Lawes of England: Containing the Exposition of Many Ancient and Other Statutes (Londres, 1642), cap. XXIX, p. 46]. 
En el final de la Edad Media y principios de la Moderna los reyes europeos consiguen acumular más poder en sus manos gracias a la pólvora y otros avances científicos y técnicos, así como por el apoyo de la incipiente burguesía, muy especialmente de los legistas, los técnicos jurídicos que ayudaron a los reyes a racionalizar el derecho contra las intromisiones de los poderes eclesiásticos y contra las prerrogativas de la nobleza ${ }^{22}$. En ese despliegue del Estado moderno, la lucha por la libertas medieval de los derechos subjetivos se sustituye por la lucha por conseguir normas generales que garanticen la libertad frente al poder político.

Sin duda, era la hora de encontrar una palabra que expresara con claridad y fuerza lo injusto que era un gobierno que pretendiera actuar sin límites y tomando solo en cuenta su propia voluntad. Por eso, donde más pronto surgió con fuerza esa lucha es donde más pronto la palabra arbitrario tomó una nueva acepción: en el convulso siglo XVII inglés en el que el Parlamento desafía el poder del rey y se inicia una lucha a muerte (literal, una guerra civil y la decapitación de Carlos I) es cuando empieza a usarse la expresión poder arbitrario para referirse críticamente a un poder que no acepta estar limitado por las leyes.

Así, por ejemplo, en la Exposición de Agravios (Petition of Grievances) de la Cámara de los Comunes al rey Jacobo I de Inglaterra, el 7 de julio de 1610 se señala que entre las fuentes de la felicidad y de la libertad para los súbditos, la que se ha considerado más querida y preciada es "la de ser conducidos y gobernados por la ley, la cual da a las autoridades su legitimidad, y no por una forma de gobierno incierta o arbitraria"23. Como el rey Jacobo tenía unas firmes creencias absolutistas, que le llevaron a recaudar impuestos y a otorgar monopolios en varias ocasiones sin la anuencia del Parlamento, los años posteriores vieron un incremento de los enfrentamientos para determinar quién desempeñaría el poder supremo ${ }^{24}$.

La desaparición de Jacobo I en 1625 no supuso el fin de estos enfrentamientos; antes al contrario, Carlos I gobernó sin tener en cuenta al Parlamento y extremando los rasgos absolutistas de su padre, hasta el punto de disolverlo tres veces y gobernar desde 1629 hasta 1640 usando sus prerrogativas regias, lo que daría lugar a que posteriormente se calificara ese período como los Eleven Years'

${ }^{22}$ Cfr. Gómez Arboleya, Enrique Estudios de teoría de la sociedad y del Estado (Madrid, 1982), pp. $410-438$.

${ }^{23}$ Apud TAnner, Joseph Robson, Constitutional Documents of the Reign of James I, 1603-1625 (Cambridge, 1930), p. 154. Posiblemente el libro más antiguo que usa a r b i t r a r i o con su significado moderno en su título sea la recopilación de los discursos parlamentarios de Sir John Holland que se publicaron en 1641: Sir Iohn Holland His Speech in Parliament. Declaring the Great and Manifold Grievances of this Kingdome, Both in Church and Commonwealth. Occasioned by the Wicked Practises and Arbitrary Power of the Disturbers and Subverters of Our Peace, Our Liberties, And Our Lawes (Londres, 1641).

${ }^{24} \mathrm{La}$ convicción absolutista de Jaime I era tan fuerte que incluso escribió un libro argumentando que el poder absoluto provenía de Dios: The True Law of Free Monarchies (1598). El ensayo se concibió como una réplica a George Buchanan, De Jure Regni apud Scotos (1579), en el que se defendía una monarquía limitada para Escocia. 
Tyranny. Cuando vuelve la vida parlamentaria - primero con el Short Parliament de 1640 y luego con el Long Parliament de 1642-1660-y se reanuda la tensión dialéctica entre los partidarios del Parlamento y los realistas se produjo lo que podríamos llamar un fenómeno político-lingüístico curioso: el poder arbitrario se convirtió en un concepto básico de la lucha política, tanto que no solo lo usó el Parlamento en la lista de quejas de la Grand Remonstrance de 1641, sino el propio rey Carlos I lo empleó en la respuesta que dio en 1642 a las peticiones del Parlamento, cuyo rechazo llevó a la Guerra Civil. Si bien, en su opinión, quien había usado arbitrariamente su poder había sido el Parlamento que no respetaba el derecho antiguo que otorgaba el poder al rey: "un nuevo Poder ha sido asumido para interpretar y declarar leyes sin Nosotros [...] actuando como un auténtico poder arbitrario" 25 .

De esa forma, las dos partes enfrentadas argumentaban simétricamente que se basaban en las leyes fundamentales del Reino y acusaban a la contraria de vulnerarlas para instaurar un poder arbitrario. Así las cosas, no es de extrañar que la prohibición de la arbitrariedad pasara de la política a la legislación. Primero implícitamente, en la Petion of Right de 1628 redactada por Edward Coke y considerada uno de los tres grandes textos constitucionales históricos ingleses (con la Carta Magna y el Bill of Rights de 1689), a pesar de que su naturaleza jurídica no estuviera muy clara, al menos al principio. En ella se enumeran derechos de los ingleses pensados para acabar con las arbitrariedades que Carlos I estaba realizando para sufragar la Guerra de los Treinta años; así, se prohibían tanto los préstamos obligatorios como los pagos de impuestos que no hubieran sido votados por el Parlamento, las detenciones sin pruebas, las ocupaciones de viviendas que hacían los soldados sin autorización de sus propietarios, etc.

La Habeas Corpus Act de 1640, que amplió los derechos reconocidos por la Petition, muy especialmente garantiza la prohibición de detenciones sin fundamento a toda la población, que ya tenía la nobleza, tampoco menciona por su nombre la arbitrariedad, lo que sí hizo la Act for the Abolition of the Court of Star Chamber de 5 de julio de 1641, que considera en su preámbulo que el tribunal de la Cámara Estrellada era un instrumento para "introduce an arbitrary power and government" y por eso, prohíbe que el rey y su consejo privado tengan "cualquier jurisdicción, poder o autoridad por ley, petición, estatutos, escritos o cualquier otra forma arbitraria, para examinar o cuestionar, determinar o disponer de las tierras, fundos, propiedades, o bienes muebles de

\footnotetext{
${ }^{25}$ Cito por https://www.constitution.org/eng/nineteen_propositions_1642.html. El Oxford English Dictionary señala que fue en esta década de 1640 cuando "arbitrary" se usa por primera vez con el sentido de "Unrestrained in the exercise of will; of uncontrolled power or authority, absolute; hence, despotic, tyrannical” (http://www.oed.com/view/Entry/10180), aunque acabamos de ver ejemplos de principio del siglo XVI. Por su parte, el Merriam-Webster Diccionary remonta su uso dos siglos, pero no cita las fuentes escritas: "The first known use of arbitrary was in the 15th century" (https://www.merriam-webster.com/dictionary/arbitrary\#other-words). Desde luego, si en el siglo XV se usó arbitrario como despótico sería de forma muy esporádica porque en el gran libro sobre el gobierno de la época De Laudibus Legum Angliae de Sir John ForTeScue (escrito alrededor de 1468-1471 y publicado en 1543) arbitrio y sus derivados se usan en su sentido clásico de decisión libre.
} 
cualquiera de los súbditos de este reino, pero que los mismos deben ser juzgados y determinados en los Tribunales ordinarios de Justicia y por el procedimiento ordinario de la ley"26.

Igualmente se menciona la arbitrariedad en la Ley de 6 de enero de 1649 que tuvo la revolucionaria idea de crear un tribunal para juzgar al rey ${ }^{27} . \mathrm{Y}$, desde luego, en el impresionante English Bill of Rights de 1689, que el príncipe Guillermo aceptó para lograr el apoyo del Parlamento inglés en su lucha por el trono tras la Gloriosa Revolución de 1688. Su catálogo de libertades va precedido de un preámbulo en el que aparece mencionada expresamente la arbitrariedad dos veces, primero cuando da cuenta de los excesos del depuesto rey Jacobo II, señala que el rey había trasladado a sus tribunales materias que le correspondían al Parlamento y que "cometió otras diversas acciones arbitrarias e ilegales"; para agregar a continuación que Inglaterra se libró de su "poder arbitrario" gracias al príncipe de Orange. Después no vuelve a aparecer la palabra, pero muchos artículos tienen la evidente finalidad de prevenir ese poder arbitrario, como son las múltiples prohibiciones que se le imponen al rey: de suspender las leyes aprobadas por el Parlamento, de recaudar tributos sin autorización, de establecer un ejército permanente, de imponer fianzas y multas excesivas, de infligir castigos crueles y desacostumbrados, etc. Por eso, se ha podido escribir con razón que el Bill of Rights fue una norma pensada para "curb future arbitrary behaviour by the Crown"28.

Con esos textos culminaba jurídicamente una actividad política incesante que a lo largo del siglo XVII se había plasmado en un buen número de vibrantes panfletos contra el poder arbitrario del rey, a favor de la soberanía de la Cámara de los Comunes y de los derechos del pueblo, escrito sobre todo por los niveladores (levellers): "England's birth-right justified: against all arbitrary usurpation, whether regall or parliamentary, or under what vizor soever" (John Lilburne, 1645); "A defiance against all arbitrary usurpations or encroachments" (Richard Overton, 1646), "A vindication of every free-man libertie against all arbitrary power and government" (William Larner, 1646), etc.

Los levellers no olvidaron incluir una recriminación del poder arbitrario en su espectacular An Agreement of the People -de gran influencia tanto en la revolución americana como en la francesa- en donde se pedía una constitución democrática para Inglaterra. Así rezaba el preámbulo de su tercera versión (de mayo de 1649): "Nosotros, el Pueblo libre de Inglaterra, a quien Dios ha dado corazones, medios y oportunidades para hacer lo mismo, con la sumisión a Su sabiduría, en Su nombre, y deseando que Su equidad sea para Su alabanza y gloria, estamos de acuerdo en determinar que nuestro Gobierno abolirá

${ }^{26}$ Cito por https:/ / oll.libertyfund.org/pages/1641-the-act-for-the-abolition-of-the-courtof-star-chamber. Sobre esta ley y, en general, sobre este período vid. Russell, Conrad, The Fall of the British Monarchies 1637-1642 (Oxford, 1991).

${ }^{27}$ En verdad la Act of the Commons of England Assembled in Parliament, for Erecting of a High Court of Justice, for the Trying and Judging of Charles Stuart, King of England preconfiguraba ya la sentencia a muerte que recibió Carlos I el 26 de enero de 1649: "Whereas it is notorious, That Charles Stuart, the now King of England, not content with those many Encroachments which his Predecessors had made upon the People in their Rights and Freedoms, hath had a wicked Design totally to Subvert the Ancient and Fundamental Laws and Liberties of this Nation, and in theirplace to introduce an Arbitrary and Tyrannical Government' (cito por https://www.british-history.ac.uk/no-series/acts-ordinancesinterregnum/pp. 1253-1255).

${ }^{28}$ Lock, Geoffrey, The 1689 Bill of Rights, en Political Studies, $37 / 4$ (1989), p. 540. 
todo poder arbitrario, y establecerá fronteras y límites tanto a nuestra Suprema Autoridad como a todas sus autoridades subordinadas, y eliminará todos los agravios conocidos"29.

Sin embargo, la gran teorización sobre la arbitrariedad llegó unos años más tarde, de la mano, o mejor de la pluma, lógicamente, de John Locke, el gran teórico del nuevo Estado liberal, que en 1689 publicó anónimamente sus Two Treatises of Government. En el primero, combate la doctrina de la monarquía absoluta de origen divino que había sido teorizada en 1680 por sir Robert Filmer en Patriarcha. Aquí Locke utiliza la arbitrariedad para describir el poder monárquico supuestamente recibido por Adán y heredado por los reyes y sacar sus lógicas consecuencias: ese poder arbitrario es "ilimitado sobre la vida, las libertades y las propiedades de sus hijos y súbditos; de modo que puede tomar o alienar sus propiedades, vender, castrar o usar a sus personas como le plazca, ya que son todos sus esclavos, y él es el señor o propietario de todas las cosas, y su voluntad ilimitada es ley"30.

En el Segundo Tratado, "un ensayo acerca del verdadero origen, alcance y fin del gobierno civil", John Locke construye una sólida teoría sobre el poder político cuyo gran antagonista es, en este caso implícito, Thomas Hobbes. Así, si para este el estado de naturaleza es la guerra de todos contra todos -el famosísimo homo homini lupus, que Hobbes tomó de Plauto- para el gran filósofo empirista en el estado de naturaleza los hombres son radicalmente iguales y existe una ley "que obliga a todos; y la razón, que es esa ley, enseña a toda la humanidad que quiera consultarla, que siendo todos los hombres iguales e independientes, ninguno debe dañar a otro en lo que atañe a su vida, salud, libertad o posesiones" ${ }^{31}$.

Según Hobbes, la forma de acabar con la guerra es el pacto social cuyo fin es entregar todo el poder al Estado, al Levitán, que por su propia esencia tenía que ser inevitablemente arbitrario, sin límites para poder alcanzar la paz y seguridad de los hombres. Sin embargo, para Locke el contrato social ni elimina los derechos de los ciudadanos, ni atribuye un poder arbitrario al Estado porque le ha sido conferido para el bien de la comunidad y, por tanto, siempre está sometido a las leyes: "todo el poder que tiene el gobierno, siendo sólo para el bien de la sociedad, no debe

\footnotetext{
${ }^{29}$ Tomo la cita de An Anthology of Leveller Tracts: Agreements of the People, Petitions, Remonstrances, and Declarations (1646-1659) de la Online Library of Liberty (https://oll.libertyfund.org/pages/ leveller-anthology-agreements). Esta Anthology de las publicaciones de los niveladores entre 1646 y 1659 permite comprobar con comodidad el amplio uso que los niveladores hicieron de arbitrary y arbitrariness. En cualquier caso, como ya he comentado con la respuesta de Carlos I a las diecinueve peticiones en 1642, el "p o d e r a r b i t r a r i o" se había convertido en una expresión de c o m b a t e para aplicar a los adversarios. Por ejemplo, el conservador y defensor de la realeza John NALSON la usa en su The complaint of liberty \& property against arbitrary government (Londres, 1681). En el impresionante catálogo de la Early English Books Online (EEBO) de la Universidad de Michigan aparecen 100 libros del siglo XVII que utilizan en su título el adjetivo "arbitrary", muchos calificando a "power" (https://quod.lib.umich.edu/e/eebogroup).

${ }^{30}$ Párrafo 9. Cito por Dos ensayos sobre el gobierno civil (ed. Joaquín Abellán, trad. Francisco Giménez Gracia, Madrid, 1991). La bibliografía sobre el pensamiento de Locke es inabarcable, quizás para nuestro estudio sobre la arbitrariedad uno de los trabajos más útiles sea HaLLDENIUS, Lena, Locke and the Non-Arbitrary, en European Journal of Political Theory, 2/3 (2003), pp. 261-279.

${ }^{31}$ Párrafo 6. Locke parece seguir aquí a Cicerón, que en su De legibus (I, 6, 18) escribió: “Lex est ratio summa, insita in natura, quae jubet ea quae facienda sunt, probibetque contraria" (La ley es la razón suma, enclavada en la naturaleza, y que ordena lo que debe hacerse y prohíbe lo contrario).
} 
ser arbitrario y a voluntad, por lo que debe ser ejercido por las leyes establecidas y promulgadas; para que tanto el pueblo pueda conocer su deber, y estar a salvo y seguro dentro de los límites de la ley, y los gobernantes también mantenerse dentro de sus límites, y no ser tentado, por el poder que tienen en sus manos, a emplearlo para otros fines" 32 . Es más, Locke admite, que en ciertas ocasiones, el poder puede ser absoluto -como el de un general sobre sus soldados- pero ni siquiera en ese supuesto el poder puede ser arbitrario, siempre estará "limitado por la razón”. Por eso, un sargento puede ordenar a un soldado que ponga en riesgo su vida en la batalla "marchando hasta la boca de un cañón", pero no podrá "ordenar a ese soldado que le dé un centavo de su dinero"33.

Por tanto, Locke configura el poder arbitrario como aquel que se ejerce más allá de las leyes (donde "empieza la tiranía"), sin regirse por la razón y sin buscar "la paz, la seguridad y el bien del pueblo", sino el simple capricho del poderoso. En sentido inverso, la libertad política consiste, lógicamente, en no estar sometido a ningún poder arbitrario y sí a las leyes que han sido aprobadas por el Parlamento, consentido previamente, y cuyo objetivo es el bien de la commonwealth, añadiendo así a la legitimidad de elección, la legitimidad de ejercicio del poder ${ }^{34}$. Una vez que Locke ha configurado así la libertad y el poder arbitrario, el resto del Segundo Tratado se dedica básicamente a justificar el derecho de resistencia a un gobierno injusto, muy especialmente al gobierno que no respeta las decisiones del Parlamento. Es decir, a justificar la Revolución Gloriosa, aspecto este que se escapa al objeto de nuestro estudio, pero que conviene tener presente para entender por qué the Father of Liberalism tuvo gran influjo en la Revolución americana ${ }^{35}$. También es muy útil tener presente que, tal como se habían producido históricamente las luchas por el poder político, en la mentalidad inglesa la institución más tentada de abusar del poder era el rey, mientras que el Parlamento era el garante de las libertades ciudadanas.

\footnotetext{
${ }^{32}$ Párrafo 137. Para una comparación de estos dos grandes filósofos, vid. Harrison, Ross Hobbes, Locke, and Confusion's Masterpiece: An Examination of Seventeenth-Century Political Philosophy (Cambridge, 2002).

${ }^{33}$ Párrafo 139. En el párrafo 202 escribió su famosa frase: “Allí donde termina la ley, empieza la tiranía", que citaré enseguida en el texto.

${ }^{34}$ Cfr. Halldenius, Lena, cit. (n. 30), p. 266. Sin embargo, para Tully la arbitrariedad de Locke no está tanto relacionada con la ley sino con la falta de límites morales: “' Arbitrary' means that the exercise of the will need not be constrained by moral reasons; that action is justified by one's inherited authority, not by demonstrating that it is conformable to rational moral principles" [TuLLy, James, An Approach to Political Philosophy: Locke in Contexts (Cambridge, 1993), p. 286].

${ }^{35}$ Sobre el influjo de Locke en la revolución americana, vid. SwANSON, Mary-Elaine, John Locke: Philosopher of American Liberty: why Our Founders Fought for "Life, Liberty, and Property" Nentura, 2012). De opinión muy distinta fue Hanna ArEndT, quien en On Revolution (New York, 1963) mantuvo que la influencia de Locke fue marginal, siendo mucho más importante la de Montesquieu. Sin entrar en la polémica, por mi cuenta y riesgo me atrevo a señalar que Locke no aparece citado ni una sola vez en los Federalist Papers, a diferencia de las reiteradas citas de Montesquieu. La obra canónica sobre las raíces intelectuales de la revolución es BAILYN, Bernard, The Ideological Origins of the American Revolution, 1968 (trad. de Víctor Méndez: Los orígenes ideológicos de la Revolución americana, Madrid, 2019).
} 


\section{LA REVOLUCIÓN AMERICANA, EL ESTADO CONSTITUCIONAL GARANTÍA CONTRA LA ARBITRARIEDAD DEL LEGISLATIVO}

Por una paradoja del destino, el propio Parlamento británico -baluarte histórico contra el despotismo- usó su poder de forma arbitraria en la legislación que aprobó para las colonias americanas en el último tercio del siglo XVIII. O al menos así lo vieron los representantes de las trece colonias reunidos en octubre de 1774 en Filadelfia, donde constituyeron el Continental Congress. Los 55 delegados, bajo la presidencia de Peyton Randolph, consideraron que el Parlamento británico les había impuesto una serie de Intolerable Acts, contra la que aprobaron una "Declaration of Righs and Grievances" en las que explicaban que habían tenido que reunirse alarmados "por los procedimientos arbitrarios del Parlamento y la Administración”, que no respetaban las leyes inmutables de la naturaleza ni "los principios de la Constitución inglesa”. En la Declaración señalaban los derechos que esa Constitución y diversas cartas le atribuían, muy especialmente su derecho a participar en el poder legislativo del Reino, del que estaban excluidas las colonias por lo que, sin pedir la independencia, reclamaban el autogobierno "en todos los casos de tributación y de política interna, con sujeción únicamente a lo negativo de su soberano, de la manera en que hasta ahora se ha utilizado y acostumbrado: pero, por la necesidad del caso, y teniendo en cuenta el interés mutuo de ambos países, admitimos la realización de esos actos del Parlamento británico, como son de buena fe, limitados a la regulación de nuestro comercio exterior"36.

Dos años después, la Declaración de Independencia de 14 de julio de 1776 vuelve a acusar a los poderes ingleses de arbitrarios, simbolizándolos en su rey, al que se acusa de actuar de forma tiránica. En la enumeración concreta de esos actos injustos hay uno especialmente interesante para nuestro trabajo: "Por abolir el libre sistema de leyes inglesas en una provincia vecina, estableciendo en ella un gobierno arbitrario y ampliando sus límites para convertirlo en un ejemplo y un instrumento idóneo para introducir la misma regla absoluta en estas colonias" 37 .

Ni en los Artículos de la Confederación de noviembre de 1777, ni en la propia Constitución americana de septiembre 1787 se vuelve a mencionar el

${ }^{36}$ Tomo el texto de https:/ / usconstitution.net/intol.html. Las quejas sobre el incumplimiento de la Constitución inglesa en América empiezan unos años antes. Así tuvo una amplia difusión el panfleto que en 1764 publicó James OTIS, The Rights of the British Colonies Asserted and Proved. Y que él mismo resumió en la frase "taxation without representation is tyranny". Sobre la justificación de la revolución americana porque el Parlamento británico estaba actuando de forma arbitraria contra la propia constitución histórica inglesa, vid. REID, John Phillip, In Legitimate Stirps: The Concept of 'Arbitrary,' the Supremacy of Parliament, and the Coming of the American Revolution, en Hofstra Law Review, 5 (1977), pp. 459-499. También (con amplio estudio de la obra de Otis), el clásico Mcilwain, Charles Howard, The American Revolution: a Constitutional Interpretation (New York, 1923).

${ }^{37}$ Cito por https://www.loc.gov/law/help/legal-reports.php\#constitution. La Declaration se refiere a Quebec, que se incorporó a la Corona británica en 1763. En 1774 el Parlamento británico aprobó la Quebec Act que garantizaba a los 90.000 habitantes de la colonia el francés, la libertad de religión (la mayoría eran católicos) y el derecho civil francés, un régimen que indignó a los colonos anglófonos, como se aprecia claramente en esta cita de la Declaración de Independencia. Sobre ella, cfr. Armitage, David, The Declaration of Independence: A Global History (Cambridge, Mass, 2007). 
gobierno arbitrario. Pero no cabe duda de que su complicado diseño de checks and balances está pensado para impedirlo, incluso recelando del propio poder del Parlamento, debido a la diferente experiencia histórica con la metrópoli: si toda la política inglesa giraba en torno al principio de la soberanía del Parlamento, hasta el punto de que Jean-Louis de Lolme pudo escribir en 1771 -con evidente exageración- que "El Parlamento inglés puede hacerlo todo menos cambiar un hombre en mujer" 38 ; el nuevo Estado americano diseñó una división de poderes pensada para que se controlen mutuamente porque -en las famosas palabras de Thomas Jefferson- "ciento setenta y tres déspotas pueden ser tan opresores como uno solo" 39 .

Alexander Hamilton añadirá a la reflexión de Jefferson que esos poderes deben ser responsables - usando casi por vez primera en inglés la palabra responsibility"frente al pueblo" y defenderá que una forma eficaz de controlar el poder legislativo sería -como había adelantado sin éxito Edward Coke a principios del siglo XVII- atribuir a los tribunales la capacidad de anular las leyes inconstitucionales porque, lejos de implicar la superioridad del poder judicial, "no sólo sirve para moderar los daños inmediatos de las ya promulgadas, sino que actúa como freno del cuerpo legislativo para aprobar otras, pues percibiendo éste los obstáculos al éxito de sus inicuos designios que son de esperarse de los escrúpulos los tribunales, se verá obligado a modificar sus intentos debido a los móviles mismos de la injusticia que medita realizar" ${ }^{40}$.

El sistema político así fundado tiene muchas diferencias con el británico, comenzando lógicamente por la existencia de una Constitución escrita, contrapuesta a la Constitución histórica inglesa, formada por la acumulación de textos y costumbres, y siguiendo por la república presidencialista y el federalismo ${ }^{41}$. Sin embargo, ambos coinciden en el sometimiento de los poderes políticos y la sociedad al derecho, el rule of law. Por eso, su visión aparente de la arbitrariedad es similar y se puede resumir en la contundente frase que en 1773 escribió John Arbuthnot: "what is not legal is arbitrary" ${ }^{42}$, pero con una diferencia esencial: para

38 "Le Parlement peut tout, excepté faire une femme d'un homme, et vice versa", LOLME, Jean-Louis de, Constitution de l'Angleterre, Tome Premier (Amsterdam, 1771), p. 126, nota 1. No deja de ser una curiosa ironía que la frase más conocida de este liberal ginebrino, situada en una nota a pie de página, le haga parecer como un duro crítico del sistema político inglés, cuando en realidad lo admiraba.

${ }^{39}$ Jefferson, Thomas, Notes on the State of Virginia, 1785, p. 195. Esta idea fue ampliamente compartida por los Fundindg Faders, tanto que James Madison la citó en el número 48 de The Federalist Papers (New York, 1788).

${ }^{40}$ Alexander Hamilton; James Madison y John Jay, The Federalist Papers (1788, trad. de Gustavo R. Velasco, El federalista, México, 2001), 78. Hamilton se refiere a la political responsibility en los números 63, 70, 77, 78 y 79 de The Federalist, que son unas de las citas más antiguas de la palabra responsibility con el significado de "The state or fact of being in charge of or of having a duty towards a person or thing" que tiene datada el Oxford English Dictionary (http://www.oed.com/ view/Entry/163862).

${ }^{41}$ Cfr., por toda la abundantísima doctrina comparatística, REID, John Phillip, Constitutional History of the American Revolution (Madison, 1995). En español, JimÉNEZ AsENSIO, Rafael, El constitucionalismo (Oñati, 2001), pp. 13 y ss.

${ }^{42}$ Arbuthnot, John, "The Freeholder's Political Catechism”, A Supplement to the Miscellaneous Works of the Late Dr. Arbuthnot (Glasgow, 1733), I, p. 9. 
los británicos esa ley es la ley emanada del Parlamento democráticamente elegido, mientras que para los americanos es la ley fundamental, la Constitución, de tal forma que las leyes ordinarias también pueden ser arbitrarias si no respetan esa "Supreme Law of the land" (en la famosa expresión de John Marshall en Marbury c. Madison).

$\mathrm{Si}$, como hemos visto, tanto en la revolución puritana inglesa y en la americana el adjetivo arbitrario se usó para calificar a un poder político que no respetaba los derechos de los ciudadanos (el rey, en Inglaterra; el Parlamento inglés, en las colonias); ese gran tratado de derecho constitucional que es The Federalist Papers -citado reiteradamente por el Tribunal Supremo americano como fuente de autoridad para interpretar la Constitución- no se olvida de señalar que, además de esta arbitrariedad política, que pueden cometer los poderes legislativo y ejecutivo, puede existir otra arbitrariedad técnica, en la que pueden incurrir los tribunales no tanto por una voluntad deliberada como por la dificultad de interpretar un ordenamiento jurídico necesariamente complejo. Y junto al problema, la solución, la permanencia de los oficios judiciales, eso que hoy en España conocemos como la inamovilidad judicial: "serán pocos los hombres en cada sociedad suficientemente versados en materia de leyes para estar capacitados para las funciones judiciales"43.

Esta lúcida explicación de Hamilton sobre la función judicial, nos lleva a señalar -aunque solo sea al desgaire, para no distraernos del objeto principal de este trabajo- la distinta composición de los poderes: si el legislativo y el ejecutivo necesitan renovarse periódicamente para acompasar su composición a la voluntad de los ciudadanos y rendirles cuentas, los miembros del poder judicial necesitan la inamovilidad y la independencia para conseguir la neutralidad técnica indispensable para aplicar las leyes al caso concreto. No siempre se puede luchar de la misma forma contra la arbitrariedad: mientras es una excelente idea limitar el tiempo que se puede ejercer la Presidencia de la República, elegir por tiempo indefinido a los magistrados del Supremo les da una independencia que tiene más ventajas que inconvenientes, como muy bien argumentó Hamilton.

\section{LA REVOLUCiÓn FRANCESA, LA LUCHA CONTRA EL GOBIERNO ARBITRARIO NO CONFÍA EN LOS TRIBUNALES}

Como es de sobra conocido, en 1748 Charles-Louis de Secondat, Baron de La Brède y de Montesquieu, tradujo con bastante originalidad y algo de imaginación el sistema político británico en el capítulo VIII del Libro IX de su inmarcesible De l'esprit des lois. Junto a su famosísima clasificación de los tres poderes que hay en cada Estado, el poder legislativo, el poder ejecutivo de los asuntos que dependen del derecho de gentes y el poder ejecutivo de los que dependen del derecho civil o poder judicial, Montesquieu también importó la nueva acepción desvalorativa de arbitrario: "Tampoco hay libertad si el poder judicial no está separado del legislativo ni del ejecutivo. Si va unido al poder legislativo, el poder sobre la vida

\footnotetext{
${ }^{43}$ Hamilton, Alexander, Núm. 78 de El federalista, cit. (n. 40).
} 
y la libertad de los ciudadanos sería arbitrario, pues el juez sería al mismo tiempo legislador. Si va unido al poder ejecutivo, el juez tendría la fuerza de un opresor" ${ }^{44}$.

Doce años después de la publicación del De l'esprit, en 1762 Jean Jacques Rousseau, otro de los grandes pilares intelectuales de la Revolución francesa ${ }^{45}$, publicó Du contrat social ou principes du droit politique donde crea el concepto de soberanía popular, apoyado en las ideas de libertad e igualdad, y basará la legitimidad de la ley en la volonté générale. Rousseau también usará el adjetivo arbitraire, si bien entiende por tal aquel poder que no se basa en la aceptación de los ciudadanos: "sería necesario para que un gobierno arbitrario se legitimara que durante cada nueva generación el pueblo fuese dueño de admitirlo o rechazarlo, entonces ese gobierno dejaría de ser arbitrario"46.

Con estos precedentes, no es extraño que en los prolegómenos de la revolución francesa se produjera -como antes en la inglesa y la americana- una eclosión de panfletos contra el poder arbitrario del rey Luis XVI. Y pocas manifestaciones concretas de ese poder arbitrario eran más evidentes que las lettres de cachet, las órdenes reservadas que el rey daba para encarcelar o desterrar sin ningún tipo de juicio a quien considerara conveniente y sin ninguna limitación temporal, muchas veces a petición de súbditos concretos, casi siempre nobles, que de esa forma se quitaban rivales molestos - $\mathrm{O}$ simplemente familiares con comportamiento deshonroso para la familia- y que sufrieron personajes tan notables como Voltaire, Diderot y Mirabeau (encarcelado por petición de su padre). Por eso, abundan las quejas contra estas lettres, empezando por el propio Mirabeau que escribió en 1778 Des Lettres de cachet et des Prisons d'état. En estos panfletos se usa la nueva palabra arbitraire, y la Assemblée nationale constituante creó en noviembre de 1789 un Comité des lettres de cachet contra esas "ordres arbitraires" que tenía el objetivo de estudiar la

${ }^{44}$ Montesquieu, De l'esprit des lois (1748, trad. de Mercedes Blázquez y Pedro de Vega, Madrid, 1984), Libro XI, Cap. VI, p. 169. Montesquieu utiliza en otras muchas ocasiones "arbitraire" con el significado de al margen de la ley: en el capítulo IV del libro II para señalar que en España y Portugal el poder del clero suponía un freno al poder arbitrario; en el capítulo XIV del Libro V para decir que la falta de leyes sucesorias en Rusia convertía en inestable el trono y "arbitraria, la sucesión"; en el capítulo XIX del libro V para señalar que la división de las magistraturas romanas en civiles y militares no fue arbitraria "sino que fue consecuencia del cambio de constitución”; etc. Cfr. Campagna, Norbert, "Arbitraire”, en Volpilhac-Auger, Catherine (dir.), Dictionnaire Montesquieu [en ligne], 2013. URL: http:/ / dictionnaire-montesquieu. ens-lyon.fr/fr/article/1377722783/fr/

${ }^{45}$ Los historiadores aceptan ampliamente la influencia de Montesquieu y Rousseau en los revolucionarios franceses. Sin embargo, Arendt mantuvo una sugerente tesis: mientras la Revolución americana tuvo la ventaja de haber tenido como modelo la división de poderes de Montesquieu; "la desgracia de la francesa, fue la dictadura de la volonté générale, que asfixia la libertad" [ARendt, Hannah, On Revolution (1963, trad. de Pedro Bravo, Sobre la revolución, Madrid, 2009), p. 251].

${ }^{46}$ Rousseau, Jean Jacques, Du contrat social ou principes du droit politique (1762, trad. de José Bullejos, El contrato social, Madrid, 1936), p. 64. Un año antes, se publicó en Holanda el primer libro en francés que lleva en su título el adjetivo arbitrario con su nuevo significado: HuERnE DE LA мOTHE, Francois-Charles, Libertés de la France, contre le pouvoir arbitraire de l'excommunication (Amsterdam, 1761); un vibrante alegato contra la excomunión de los comediantes en general y muy especialmente, los de la comedia francesa, que le costó a su autor la arbitraria prohibición de ejercer la abogacía en Francia. 
mejor forma de "rendre la liberté aux victimes du pouvoir arbitraire qui gémissent encore dans les fers", problema complicado pues se temía que si se decretaba la puesta en libertad inmediata de todos los encarcelados por ellas - de forma análoga a la abolición del feudalismo que se había hecho en agosto de 1789- aumentara la inestabilidad social y se incrementaran exponencialmente los delitos ${ }^{47}$.

Lógicamente, el gran texto revolucionario, la Déclaration des droits de l'homme et du citoyen de 26 de agosto de 1789 es en sí mismo un instrumento contra el poder arbitrario tanto porque reconoce unos derechos naturales, que todos los poderes públicos deben respetar, como porque proclama, siguiendo a Montesquieu, la división de poderes en su archifamoso artículo 16: "Toute société dans laquelle la garantie des droits n'est pas assurée, ni la séparation des pouvoirs déterminée, n'a point de Constitution". En el artículo 7 se establece el principio de legalidad de las detenciones y se prohíben las lettres de cache y cualquier orden de detención que no esté basada en la ley: "Nul homme ne peut être accusé, arrêté ni détenu que dans les cas déterminés par la loi, et selon les formes qu'elle a prescrites. Ceux qui sollicitent, expédient, exécutent ou font exécuter des ordres arbitraires, doivent être punis" ${ }^{\prime 4}$. El artículo 16 de la Constitución de 3 de septiembre de 1791, reforzando lo establecido en la Declaración, era especialmente garantista porque no solo exigía que las detenciones se hicieran de acuerdo con la ley exclusivamente por las autoridades previstas, sino que agregaba que si el lugar de detención no era público y expresamente señalado por la ley entonces quien hubiera realizado esa detención "seront coupables du crime de détention arbitraire".

Precisamente, hablando de la ley, Eduardo García de Enterría ha notado que la Déclaration consagra la ley con una fuerza teórica y una importancia en el ordenamiento jurídico que no se le había dado en el mundo anglosajón: ella define el ámbito de actuación de los ciudadanos, que pueden hacer todo lo que no está prohibido en la ley, cuyo objeto es asegurar el goce de los derechos (art. 4) y por eso solo puede prohibir las acciones perjudiciales para la sociedad (art. 5); la ley es expresión de la voluntad general, que debe formarse con la participación de todos los ciudadanos y tener carácter general y siendo todos los ciudadanos

${ }^{47}$ Cfr. Castellane, Boniface Louis André, Rapport au nom du Comité des lettres de cachet (Paris, 1790). Vid. JANDEAux, Jeanne-Marie, La révolution face aux «victimes du pouvoir arbitraire»: l'abolition des lettres de cachet et ses consequences (1789-1792), en Annales Historiques de la Révolution Française, 368 (2012), DOI: 10.4000/ahrf.12293. El Rapport, Des Lettres de cachet de Mirabeau y otros muchos documentos de la Revolución están recopilados en Internet en la Newberry French Pamphlet Collection (https://archive.org/details/newberryfrenchpamphlets). Ahí puede consultarse el interesante libro de Sanchamau, Jean Baptiste, L'école des peuples et des rois, ou Essai philosophique sur la liberté, le pouvoir arbitraire, les juifs et les noirs (Paris, 1790) donde se defiende la libertad de los judíos y de los africanos esclavizados, si bien de forma progresiva, para lo que estudia el movimiento abolicionista cuáquero americano.

${ }^{48}$ Lamentablemente los revolucionarios no cumplieron este artículo 7 y abundaron las detenciones arbitrarias. Posiblemente la más importante, tanto que fue una quiebra de la nueva legalidad y abrió las puertas al Terror, fue la detención de 29 diputados girondinos el 2 de junio de 1793. Para una de los protagonistas, Madame de STAËL, este devenir de la revolución llevó a un resultado paradójico, que le hace preguntarse por qué "un pays longtemps gouverné par un pouvoir arbitraire a été livré, pendant une révolution, à des hommes que le pouvoir arbitraire avait corrompus?" [Considérations sur les principaux événements de la révolution française (2a ed, Paris, 1818), III, p. 387]. 
iguales ante ella (art. 6); ella regula las causas de detención (art. 7) y los delitos y las penas (art. 8), los límites a las libertades de opinión y religión solo se pueden establecer en la ley con el fin de mantener el orden público (art. 10), etc. En fin, como dice de forma expresiva García de Enterría: la Declaración consagra el "reino de la ley", lo que supone que "en lugar de los hombres, en adelante van a mandar las leyes" $"$.

Por mi cuenta, añado que esa posición de la ley, ese légicentrisme absolu, deja a la Constitución sin opciones de convertirse en una fuente del derecho capaz de controlar a la ley. Por decirlo en términos franceses: los droits de l'homme se garantizan en la ley, que a su vez los limita y contra la que no existen mecanismos para comprobar si los ha desarrollado correctamente ${ }^{50}$. Frente a la Constitución normativa estadounidense, las constituciones francesas -y con ellas las del resto de Europa- serán por muchos años constituciones programáticas. Es más, si en lugar de pensar en términos de fuentes del derecho, pensamos en términos de división de poderes, nos daremos cuenta, como el gran maestro administrativista cántabro señaló, que la devoción por la ley que mostraron los revolucionarios franceses era producto de un profundo recelo, o incluso animadversión, hacia los tribunales, tanto que "la enemiga a la jurisprudencia judicial acompañó por ello el advenimiento de la ley" "51. Sin duda, ese recelo provenía de la herencia ideológica de Montesquieu, que había declarado que el poder judicial debía ser un "poder nulo" cuya función era la de pronunciar "las palabras de la ley", mediante sentencias "que deben corresponder siempre al texto expreso de la ley". Pero también de la experiencia histórica de unos tribunales -los Parlements-controlados por la nobleza y que aplicaban arbitrariamente el derecho del Ancien Régime en beneficio propio. Por eso, la Asamblea Nacional Constituyente aprobó en agosto de 1790 la Ley de Organización Judicial (conocida como Loi sur l'organisation judiciaire des 16-24 août 1790) que sustituyó los Parlements por tribunales nombrados por el Estado a los que les prohibió tanto hacer reglamentos como - con una visión de la división de poderes completamente desconocida en el mundo anglosajón- controlar a la Administración y les ordenó que se dirigieran "al cuerpo legislativo todas las veces que lo crean necesario, bien para interpretar una ley, bien para hacer una nueva" 52 .

Una vez pasado los grandes momentos revolucionarios, los nuevos poderes públicos tuvieron que empezar a realizar sus funciones cotidianas (aunque durante muchos años, entre estas la principal fuera la guerra con los Estados vecinos) y en ese trabajo cotidiano se advirtió un problema con la Administración: si la división de poderes impide que el Poder Judicial la controle, se produce el riesgo evidente de que realice actuaciones más allá de las fronteras de la ley. Pero más

\footnotetext{
${ }^{49}$ García de Enterría, Eduardo, La lengua de los derechos. La formación del derecho público europeo tras la Revolución Francesa (Madrid, 1994), p. 141.

${ }^{50}$ Cfr. RoulHac, Cédric, Les droits de l'homme sans la loi? Conception(s) et effectivité des droits de l'homme en droit français, en La Revue des Droits de l'Homme, 5 (2014), DOI: 10.4000/revdh.741.

${ }^{51}$ GARCía dE EnTERría, Eduardo, cit. (n. 49), p. 146. Las referencias que enseguida se harán a Montesquieu están en el ya citado Capítulo VI del Libro XI.

${ }^{52}$ Vid. LAfon, Jacqueline Lucienne, La Révolution française face au système judiciaire d'Ancien Régime (Paris, 2001).
} 
todavía, incluso actuando con sujeción a la ley, la Administración necesita un arbitraire inévitable en muchas de sus decisiones, como fácilmente se puede apreciar en materia de personal, subvenciones, etc. Paradójicamente Napoleón, que no se preocupó mucho por la arbitrariedad política que detentaba, vio el problema de esa arbitrariedad administrativa y, al mismo tiempo, propuso la solución: "quiero instituir un órgano medio administrativo, medio judicial, que regule el uso de esta parte de la arbitrariedad necesaria en la administración del Estado; esta arbitrariedad no puede dejarse en manos del príncipe, porque la ejercerá mal o no la ejercerá" 53 .

Napoléon pasó de las palabras a los hechos enseguida: un decreto de 11 de junio y otro de 22 de julio de 1806 organizaron la jurisdicción contenciosoadministrativa, que todavía se mantiene y de la que España es especialmente deudora $^{54}$. Además, el derecho, con la precisión de un gran cirujano, distinguió entre la discrecionalidad admitida y la arbitrariedad prohibida. Pero, llegados a este punto, es hora de que hablamos algo de nuestro país.

\section{Las Cortes de CÁdiz: Siguen la eSTEla FranCESA}

DE LA LUCHA CONTRA LA ARBITRARIEDAD

El cambio del Antiguo Régimen al Moderno no se hizo en España de golpe, como sucedió en Francia. Sin embargo, y a pesar de las discusiones académicas sobre si hubo o no revolución burguesa en España, no hay muchas dudas de que a lo largo del siglo XIX se acabó con el feudalismo, los viejos señoríos territoriales se transformaron en propiedades capitalistas y el poder político absoluto se sustituyó por un régimen liberal. Por decirlo con las palabras de Carlos Marx: "España jamás ha adoptado la moderna moda francesa, tan extendida en 1848, consistente en comenzar y realizar una revolución en tres días. Sus esfuerzos en este terreno son complejos y más prolongados" ${ }^{\prime 55}$.

En este largo tránsito a la modernidad, no podía faltar la incorporación de nuevas palabras en el vocabulario político, entre las que destaca el adjetivo liberal, que España ha dado al mundo ${ }^{56}$. Lógicamente, el adjetivo arbitrario tomó el

\footnotetext{
${ }^{53}$ Pelet de la Lozère, Josep, Opinions de Napoléon sur divers sujets de politique et d'administration, recueillies par un membre de son conseil d'état; et récit de quelques événements de l'époque (Paris, 1833), pp. 190-191.

${ }^{54}$ Cfr. Rosado Pacheco, Santiago (coord.), Modelos europeos de justicia contencioso-administrativa (Madrid, 2007,) in totum; en especial para España, p. 17 y ss. y para Francia, p. 263 y ss.

${ }^{55}$ Marx, Karl, Revolutionary Spain, en New York Daily Tribune (1854). Cito por La España revolucionaria (Madrid, Alianza Editorial, 2014), p. 5. Sobre este proceso de cambio del Antiguo al nuevo Régimen, cfr. ARtola, Miguel, Antiguo régimen y revolución liberal (3ª ed., Barcelona, 1991).

${ }^{56}$ Vid. Cruz SeOAne, María, Elprimer lenguaje constitucional español (Las Cortes de Cádia) (Madrid, 1968). El texto más antiguo del catálogo de la Biblioteca Nacional que recoge a r b i t r a r i o con su nuevo significado proviene de un ilustrado mejicano, conocedor de las ideas políticas de los EEUU: Don Francisco Xavier de Gamboa, del Consejo de S.M. Regente de la Real Audiencia de esta Nueva España. Por quanto con el fin de evitar el abuso, y arbitrariedad con que ha solido procederse por algunos Tribunales.. he tomado... las providencias que he tenido conveniente (s. 1., 1793) (http://catalogo. bne.es/uhtbin/cgisirsi/?ps=sUrrg5DKEu/BNMADRID/115100938/123).
} 
significado que ya hemos visto que tomaba en inglés y en francés al ritmo que avanzaba la lucha contra los poderes sin límites legales. Además, los autores españoles gustaron del sustantivo arbitrariedad, muy poco usado por franceses y angloparlantes; hasta el punto de usarlo la propia Junta Suprema Central en su Decreto sobre restablecimiento y convocatoria de Cortes expedido por la Junta Suprema gubernativa del Reino (“Consulta al país”) de 22 de mayo de 1809: "Queriendo, pues, el Rey nuestro señor, Don Fernando VII, y en su Real nombre la Junta Suprema gubernativa del Reino, que la Nación española parezca a los ojos del mundo con la dignidad debida a sus heroicos esfuerzos, resuelta a que los derechos y prerrogativas de los ciudadanos se vean libres de nuevos atentados, y a que las fuentes de felicidad pública, quitados los estorbos que hasta ahora las han obstruido, corran libremente luego que cese la guerra, y reparen cuanto la arbitrariedad inveterada ha agostado y la devastación presente ha destruido, ha decretado lo que sigue: 1 . Que se restablezca la representación legal y conocida de la Monarquía en sus antiguas Cortes $[\ldots]^{\prime \prime 57}$.

A partir de ahí, la arbitrariedad -muchas veces calificada de negra y otros adjetivos desestimativos-, el poder arbitrario y el gobierno arbitrario aparecerán con frecuencia en los debates parlamentarios gaditanos ("el despotismo se sucedió en el Trono y a la ley sucedió la arbitrariedad", dijo en un debate el diputado Manuel García Herreros), el Discurso preliminar de Agustín de Arguelles a la Constitución ("la freqüente reunion de Córtes era un verdadero obstáculo á la arbitrariedad), panfletos, periódicos, etc. ${ }^{58}$, hasta llegar al primer texto jurídico español que -si no aceptamos el Estatuto de Bayona de 1808 como un texto español- incluye la arbitrariedad, el Decreto de 10 de Noviembre de 1810, sobre la Libertad política de la Imprenta, que tiene este corto pero expresivo preámbulo: "Atendiendo las Córtes generales y extraordinarias á que la facultad individual de los ciudadanos

57 Cito por http://www.cervantesvirtual.com/servlet/SirveObras / c1812/90251731092370596454679/p0000001.htm\#I_1. El autor material de este decreto fue Manuel José Quintana, que ya había usado previamente a r b i t r a r i e d a d en el Semanario Patriótico, el primer periódico político español que se publicó de septiembre de 1808 hasta marzo de 1812. Así, por ejemplo: "Nuestros padres sucumbieron en la contienda gloriosa que empeñaron para defender sus fueros y libertades; y nos legaron la arbitrariedad monstruosa, que cimentada por tres siglos de sufrimiento de una parte y de usurpaciones e injusticias por otra" (9, de 27 de octubre de 1808). Además, el decreto se basó en una propuesta de Lorenzo Calvo de las Rozas, que al año siguiente escribió un libro titulado El patriotismo perseguido a traición por la arbitrariedad y el egoísmo (Cádiz, 1810).

${ }^{58} \mathrm{Cfr}$. la interesante recopilación de todas estas fuentes que hace FERNÁNDEZ, Tomás-Ramón, cit. (n. 1), p. 60 y ss. Por mi cuenta, añado esta catastrófica descripción del Absolutismo español que hizo El imparcial o Gazeta política y literaria de Madrid: "El vicio radical estaba en el sistema establecido: no teníamos constitución: todo era arbitrariedad: no había distinción de poderes: la administración de hacienda era un caos: los gastos, aún ordinarios, eran tan exorbitantes, que las rentas y los excesivos impuestos no cubrían la mitad de ellos: la deuda nacional era enorme, y era preciso que fuese cada día en aumento. Sin embargo, no teníamos marina ni exército correspondientes á la defensa de tan vastos estados: la administración de la justicia estaba tiranizada por el favor y la intriga: la instrucción pública en la mayor barbaridad: la educación del pueblo abandonada: la agricultura oprimida: la industria y el comercio encadenados con indisolubles trabas" (8 de junio de 1809). 
de publicar sus pensamientos é ideas políticas es, no solo un freno de las arbitrariedad de los que gobiernan, sino también un medio de ilustrar á la Nación en general, y el único camino para llevar al conocimiento de la verdadera opinión pública, han venido en decretar [...]"59.

En el frente contrario, el de los afrancesados seguidores de José I, también se utilizó el nuevo significado de arbitrariedad. Así, Miguel José de Azanza, presidente de la Diputación Permanente que aceptó el 7 de julio de 1808 en Bayona la Constitución que les presentó Napoleón, ofreció esta descripción del Antiguo Régimen: "El orden social estaba a punto de disolverse entre nosotros; el Gobierno superior lo había atraído todo a sí para ensanchar más los límites de la arbitrariedad, escoger los negocios en que pudiera hacerse lugar la parcialidad o el capricho y dejar los demás en abandono" ${ }^{60}$. El propio José I afirmó, ya en Madrid, que no quería gobernar "con cetro de hierro y con leyes arbitrarias, sino con una constitución dulce" ${ }^{\prime 1}$. Ni que decir tiene que los patriotas ya se habían adelantado en tildar el nombramiento de José I como "arbitrario, escandaloso y nulo"62. En fin, una vez adoptado el nuevo significado de arbitrario, incluso los partidarios del Antiguo Régimen hicieron suya la palabra y la usaron contra aquellos que "trayendo solo en la boca el nombre de Patria, empuñan en su mano la tea de la discordia, para encender el fuego de una revolución sanguinaria, con la bárbara idea de acabar con aquella llorosa madre, y con las santísimas instituciones de una Religión"63.

Precisamente, esta Constitución -técnicamente una carta otorgada y no una constitución propiamente dicha elaborada por un poder constituyente ${ }^{64}-$ tiene

${ }^{59}$ Merece la pena reproducir la apasionada defensa de este decreto que hizo Muñoz Torrero en las Cortes el 14 de octubre de 1810: “creo que haríamos traicion á los deseos del pueblo, y que daríamos armas al gobierno arbitrario que hemos empezado á derribar, si no decretásemos la libertad de imprenta" [ApudQueipo de Llano Ruiz de Saravia, Conde de Toreno, José María, Historia del levantamiento, guerra y revolución de España (Madrid, 1839), II, p. 243. Vid. FERnÁNDEZ SEGAdo, Francisco, La libertad de imprenta en Cádiz: Historia y Derecho (1808-1812). De una libertad sin marco legal a una libertad constitucionalizada (Madrid, 2016).

${ }^{60}$ Actas de Bayona, Junta Duodécima del 18 de julio de 1808. Apud SAnz Cid, Carlos, La Constitución de Bayona: labor de redacción y elementos que a ella fueron aportados, según los documentos que se guardan en los Archives Nationales de París y los papeles reservados de la Biblioteca del Real Palacio de Madrid (Madrid, 1922), p. 159. No deja de llamar la atención que esta catastrófica descripción del Gobierno de Carlos IV esté hecha, precisamente, por el que había sido su Secretario de Hacienda y antes, Virrey de Nueva España.

${ }^{61}$ Gazeta de Madrid del viernes 27 de enero de 1809. No parece que José I consiguiera este gobierno de leyes, o al menos no lo vieron así los opositores: "no puede sostenerse por leyes justas y equitativas: necesita de decretos que infundiendo el terror, obliguen al silencio, ya que la usurpación los ha obligado al odio. No esperemos ver en sus decretos ningún vestigio de justicia, sino la arbitrariedad de los déspotas" (El espectador de Sevilla, 16 de octubre de 1809).

${ }^{62}$ La verdad a España, panfleto anónimo publicado en Sevilla en junio de 1808 (consultado en https://archive.org/details/laverdadespaa00unkn).

${ }^{63}$ Anónimo, La Arbitrariedad e injusticia del odio de los filósofos de España a los Institutos Regulares manifestada al más justo de los monarcas, el Sr. D. Fernando VII (Manresa, 1813), p. 4.

${ }^{64}$ El Preámbulo de la Constitución (publicada de una forma nada solemne en La Gazeta de Madrid en cuatro números, los comprendidos del 27 al 30 de julio de 1808) demuestra este carácter de carta otorgada: "En el nombre de Dios Todopoderoso: Don José Napoleón, por la gracia de 
una referencia a la arbitrariedad que entronca con la punición de las detenciones ilegales establecido en artículo 11 de la Constitución francesa de 1791, que se citó más arriba. Dice así el artículo 132 de Bayona: "Todos aquellos, que no babiendo recibido de la ley la facultad de hacerprender, manden, firmen y ejecuten la prisión de cualquiera persona, todos aquellos, que aun en el caso de una prisión autorizada por la ley reciban o detengan al preso en un lugar, que no esté pública y legalmente destinado a prisión, y todos los alcaides y carceleros que contravengan a las disposiciones de los tres articulos precedentes, incurrirán en el crimen de detención arbitraria”. Bien porque los constituyentes de Cádiz se inspiraran en este texto - cosa que en general no hicieron- bien porque tomaran el texto directamente de la Constitución revolucionaria de 1791, lo cierto es que la venerable Constitución de 19 de marzo de 1812 ordenaba algo muy similar en su artículo 299: "El juezy el alcaide que faltaren á lo dispuesto en los articulos precedentes, serán castigados como reos de detención arbitraria, la que será comprendida como delito en el código criminal'. Esta extrema garantía contra las detenciones solo será seguida por una de nuestras Constituciones históricas, la progresista de 1869: "La Autoridad gubernativa que infrinja lo prescrito en los artículos $2^{\circ}, 3^{\circ}, 4^{\circ}$ y $5^{\circ}$, incurrirá según los casos, en delito de detención arbitraria o de allanamiento de morada" (art. 9). En fin, la sexta edición del Diccionario de la Real Academia Española de 1822 recogió por primera vez la definición de arbitrario como "proceder o dictamen según el propio capricho y contra las reglas de la razón”.

Con todos los altibajos que tuvo la instauración de la monarquía liberal en España - primero, reinstauración del Absolutismo a la vuelta de Fernando VII en mayo de 1814 y hasta el pronunciamiento de Riego el 1 de enero de 1820; después, la década ominosa 1823-1833- lo cierto es que la lucha contra la arbitrariedad siguió en España un camino similar al seguido en Francia: proclamación de derechos y división de poderes en las Constituciones para evitar la máxima arbitrariedad política, el gobierno absoluto o despótico; papel central de la ley en el ordenamiento jurídico - con desplazamiento de la Constitución al campo de los principios- para garantizar la eficacia de los derechos de los ciudadanos y delimitar la actuación de la Administración y los tribunales, que debían de "aplicar puntualmente las leyes", huyendo de interpretaciones arbitrarias, que en la Constitución de Cádiz se llevó hasta el extremo de establecer que cuando los tribunales tuvieran dudas sobre "la inteligencia de alguna ley" deberían de consultar a las Cortes para que realizarán "la conveniente declaración" (art. 262.10). Por último, el sistema jurídico será completado con el establecimiento de los tribunales contenciosos para controlar la arbitrariedad de las administraciones públicas, que se consagró en la Ley de la Jurisdicción Contencioso-Administrativa de $1845^{65}$. Muchos años

Dios, Rey de las Españas y de las Indias: Habiendo oído a la Junta nacional, congregada en Bayona de orden de nuestro muy caro y muy amado bermano Napoleón, Emperador de los franceses y Rey de Italia, protector de la Confederación del Rhin, etc. Hemos decretado y decretamos la presente Constitución, para que se guarde como ley fundamental de nuestros Estados y como base del pacto que une a nuestros pueblos con Nos, y a Nos con nuestros pueblos" (puede consultarse en http://www.cervantesvirtual.com/descargaPdf/ gazeta-de-madrid-99).

${ }^{65}$ Cfr. FernÁndez Torres, Juan Ramón, Historia legal de la jurisdicción contencioso-administrativa (1845-1898) (Madrid, 2007). 
después, en la Constitución de 1978 cambiaría ese paradigma: la Constitución incluye expresamente la prohibición de la arbitrariedad -gracias a una enmienda en el Senado del profesor Lorenzo Martín-Retortillo, discípulo de García de Enterría-, ordena la plena integración de la jurisdicción ordinaria en el Poder Judicial y ella misma se transforma en una fuente directa de derechos para los ciudadanos y límites para los poderes públicos, una Constitución normativa. Pero todo eso, como decía Michael Ende en la Historia interminable, es ya otra historia.

\section{ConClusiones}

La reflexión de Ihering sobre el avance del derecho a base de la lucha continua por acabar con las injusticias, tanto abstractas como individuales ${ }^{66}$, es especialmente certera en el caso del control del poder político arbitrario, que por su propia esencia nunca ha cedido limitarse voluntariamente. Por eso, los grandes avances en su control se han producido tras violentos enfrentamientos. Simplificando un tanto la complejidad histórica, podemos decir que las tres revoluciones modernas en el mundo occidental, la inglesa, la americana y la francesa buscaron acabar con el poder arbitrario, entendido como aquel que no aceptaba limitarse por leyes y con independencia de su ejercicio, sea este beneficioso o no, porque se realiza al margen de la voluntad de los ciudadanos. Dicho con las palabras de Diderot, el gran enciclopedista: "El gobierno arbitrario de un príncipe justo e ilustrado siempre es malo [...] ¿Qué caracteriza al déspota? ¿Es la bondad o la maldad? De ninguna manera; estas dos nociones no entran en su definición. Es el alcance y no el uso de la autoridad lo que se arroga" ${ }^{67}$.

Una vez eliminado el Antiguo Régimen, estas revoluciones centraron sus preocupaciones en distintos aspectos del nuevo ordenamiento jurídico: la revolución inglesa, enemiga acérrima del poder del rey, puso el acento en la soberanía parlamentaria; la Revolución americana, defraudada del Parlamento inglés, en el equilibrio de poderes y la francesa, recelosa de los tribunales, en la ley y la separación de poderes. Estas posiciones llevaron a desarrollos institucionales diferentes: en el Reino Unido mientras el Parlamento era limitado por los usos y costumbres parlamentarios, que de facto le impedían derogar leyes básicas formalmente equiparables a las demás leyes, el rule of law dio un amplio margen de actuación a los tribunales. En los Estados Unidos, la posición de los tribunales se vio reforzada por su papel de garante de la superioridad de la Constitución; además, la efectiva división del poder político, tanto entre las instituciones del Congreso y del presidente, como entre la Federación y sus Estados miembros, supuso un freno eficaz al poder arbitrario. En Francia -y España, fiel reflejo de este modelo- el papel central de la ley y el régimen parlamentario tradicional

${ }^{66}$ IHERING, Rudolf von, Der Kampf ums Recht (1872, trad. de Adolfo Posada: La lucha por el derecho, Madrid, 1985). Ihering define la injusticia como "una acción arbitraria; un ataque contra la idea de derecho" (p. 78).

${ }^{67}$ Diderot, Denis, Réfutation d'Helvetius (1774, Texte établi par J. Assézat et M. Tourneu, Paris), 1875. Cito por https:// fr.wikisource.org/wiki/R $\%$ C3\%A9futation_d $\%$ E2\%80\% $\% 9$ Helv\%C3\%A9tius/Texte_entier\#cite_ref-87. 
hicieron que los contrapesos del poder político fueran mínimos, más derivados de la lucha entre partidos políticos que de un control recíproco eficaz de las instituciones. Más éxito tuvo la jurisdicción contencioso-administrativa en el control de la arbitrariedad de las administraciones públicas.

Por esa incapacidad de controlar jurídicamente la arbitrariedad del poder político democrático que, en general, sucedía en todos los Estados europeos, Hans Kelsen propuso a principios del siglo XX la creación de un Tribunal Constitucional que revisara -solo si había controversia política- si una determinada ley se había mantenido dentro de los límites de la constitucionalidad. La progresiva aceptación de esta teoría en Europa ha supuesto la transformación de las constituciones programáticas en constituciones normativas, que aunque no está exenta de problemas, sin duda supone un avance importante en la larga e inacabable lucha por controlar el poder arbitrario y garantizar la libertad de los ciudadanos.

\section{BiBLIOGRAFíA}

Arbuthnot, John, A Supplement to the Miscellaneous Works of the Late Dr. Arbuthnot (Glasgow, 1733).

Arendt, Hannah, On Revolution (1963, trad. de Pedro Bravo, Sobre la revolución, Madrid, 2009).

Armitage, David, The Declaration of Independence: A Global History (Cambridge, Mass, 2007).

ARTola, Miguel, Antiguo régimen y revolución liberal (3a ed., Barcelona, 1991).

BAILYN, Bernard, The Ideological Origins of the American Revolution (1968, trad. de Víctor

Méndez, Los orígenes ideológicos de la Revolución americana, Madrid, 2012).

Bracton, Henry de, De legibus et consuetudinibus Angliae (c. 1220, edited by George Woodbine, Cambridge, Mass., 1968).

Carawan, Edwin, Rhetoric and the Law of Draco (Oxford, 1998).

CoKE, Edward, The Second Part of the Institutes of the Lawes of England: Containing the Exposition of Many Ancient and Other Statutes (Londres, 1642).

Croft, Pauline, King James (Basingstoke, 2003).

Cruz Seodne, María, Elprimer lenguaje constitucional español (Las Cortes de Cádiə) (Madrid, 1968).

Danziger, Danny and Gillingham, John, 1215: The Year of Magna Carta (Londres, 2004).

Ebel, Wilhelm, Die Willkür. Eine Studie zu den Denkformen des älteren deutschen Rechts (Göttingen, 1953).

FERnández, Tomás-Ramón, Arbitrario, Arbitraire, Arbitrary. Pasado y presente de un adjetivo imprescindible en el discurso jurídico (Madrid, 2016).

Fernández Segado, Francisco, La libertad de imprenta en Cádiæ: historia y derecho (18081812). De una libertad sin marco legal a una libertad constitucionalizada (Madrid, 2016).

FERNÁNDEZ TORRES, Juan Ramón, Historia legal de la jurisdicción contencioso-administrativa (1845-1898) (Madrid, 2007).

García de EnTERría, Eduardo, La lengua de los derechos. La formación del derecho público europeo tras la Revolución Francesa (Madrid, 1994).

García Pelayo, Manuel, La idea medieval del derecho (1962, Caracas, 2004).

Gómez Arboleya, Enrique, Estudios de teoría de la sociedad y del Estado (Madrid, 1982). 
Gutiérrez García, Cándida, Receptum arbitri (Alicante, 1990).

Halldenius, Lena, Locke and the Non-Arbitrary, en European Journal of Political Theory, 2/3 (2003), pp. 261-279.

Harries, Jill, Law and Empire in Late Antiquity (Cambridge, 2001).

Harrison, Ross, Hobbes, Locke, and Confusion's Masterpiece: An Examination of SeventeenthCentury Political Pbilosophy (Cambridge, 2002).

Hamilton, Alexander; Madison, James y Jay, John, The Federalist Papers (1788, trad. de Gustavo R. Velasco: El federalista, México, 2001).

Ihering, Rudolf von, Der Kampf ums Recht (1872, trad. de Adolfo Posada: La lucha por el derecho, Madrid, 2016).

Jandeaux, Jeanne-Marie, La révolution face aux "victimes du pouvoir arbitraire": l'abolition des lettres de cachet et ses consequences (1789-1792), en Annales Historiques de la Révolution Française, 368 (2012), DOI: 10.4000/ahrf.12293.

Jefferson, Thomas, Notes on the State of Virginia (Londres, 1785).

—Letter to Adamantios Coray, 31 October 1823 (https:// founders.archives.gov/documents/Jefferson/98-01-02-3837.

Jellinek, Georg, Allgemeine Staatslehre (1905, trad. de Fernando de los Ríos: Teoría general del Estado, Buenos Aires, 1981).

JimÉnez Asensio, Rafael, El constitucionalismo (Onati, 2001).

Jones, Dan, Magna Carta: The Birth of Liberty (Londres, 2016).

KEACH, William, Arbitrary Power: Romanticism, Language, Politics (Princeton, 2005).

Keresztes, Paul, Law and Arbitrariness in the Persecution of the Christians and Justin's First Apology, en Vigiliae Christianae, 17/1 (1963), pp. 204-214.

LAFON, Jacqueline Lucienne, La Révolution française face au système judiciaire d'Ancien Régime (Paris, 2001).

LeE, Simon, Lord Denning, Magna Carta and Magnanimity, en Denning Law Journal, 27 (2015), pp. 106-129.

LETwIn, Shirley Robin, On the History of the Idea of Law (Cambridge, 2005).

Lock, Geoffrey, The 1689 Bill of Rights, en Political Studies, 37/4 (1989), pp. 540-561.

Locke, John, Two treatises of government, 1690 (ed. Joaquín Abellán, trad. Francisco Giménez Gracia, Dos ensayos sobre el gobierno civil, Madrid, 1991).

Lolme, Jean Louis de, Constitution de l'Angleterre (Amsterdam, 1771).

López de OÑAte, Flavio, La certezza del diritto, Nuova edizione, in aggiunta saggi di Capograssi, Calamandrei, Carnelutti e Fedele, a cura di Guido Astuti, Appendice di M. Corsale (1942, Milán, 1968).

May, Christopher, The Rule of Law: Athenian Antecedents to Contemporary Debates, en Hague Journal on the Rule of Law, $2 / 4$ (2012), pp. 235-251.

Martín Minguijón, Ana, Digesto. Una auténtica obra legislativa (Madrid, 2013).

MCIlwarn, Charles Howard, Constitutionalism and the Changing World (Cambridge, 1939).

-The American Revolution: a Constitutional Interpretation (New York, 1923).

Montesquieu, De l'esprit des lois (1748, trad. de Mercedes Blázquez y Pedro de Vega, Madrid, 1984).

NALSON, John, The complaint of liberty \& property against arbitrary government (Londres, 1681).

Pelet de la Lozère, Josep, Opinions de Napoléon sur divers sujets de politique et d'administration, recueillies par un membre de son conseil d'état; et récit de quelques événements de l'époque (Paris, 1833). 
Ramis Serra, Pedro y Ramis Barceló, Rafael (trad. y notas), El libro de los juicios (Liber iudicorum) (Madrid, 2015).

ReID, John Phillip, In Legitimate Stirps: The Concept of 'Arbitrary', the Supremacy of Parliament, and the Coming of the American Revolution, en Hofstra Law Review, 5 (1977), pp. 459-499.

—Constitutional History of the American Revolution (Madison, 1995).

Rosado Pacheco, Santiago (coord.), Modelos europeos de justicia contencioso-administrativa (Madrid, 2007).

RousseAu, Jean Jacques, Du contrat social ou principes du droitpolitique (1762, trad. de José Bullejos, El contrato social, Madrid, 1936).

Roulhac, Cédric, Les droits de l'homme sans la loi? Conception(s) et effectivité des droits de l'homme en droit français, en La Revue des Droits de l'Homme, 5 (2014), DOI: 10.4000/ revdh.741.

Ruiz Robledo, Agustín, La abolición de los señorios, en Revista de Derecho Politico, 20 (1983-84), pp. 121-150.

Russell, Conrad, The Fall of the British Monarchies 1637-1642 (Oxford, 1991).

SAndefur, Timothy, Love and Solipsism: Law and Arbitrary Rule in Aeschylus, Shakespeare, Sophocles, and Anouilh, en Alabama Law Review, 64/5 (2013), pp. 1004-1011.

STAËL, Madame de, Considérations sur les principaux événements de la révolution française $\left(2^{\mathrm{a}}\right.$ ed, Paris, 1818).

STARCK, Christian (comp.), Recht und Willkür (Tubingen, 2012).

Swanson, Mary-Elaine, John Locke: Philosopher of American Liberty: why Our Founders Fought for "life, Liberty, and Property" (Ventura, 2012).

TAnner, Joseph Robson, Constitutional Documents of the Reign of James I, 1603-1625 (Cambridge, 1930).

Tully, James, An Approach to Political Philosophy: Locke in Contexts (Cambridge, 1993). WyducKel, Dieter, Princeps Legibus Solutus. Eine Untersuchung zur frühmodernen Rechts- und Staatslehre (Berlin, 1979). 